\title{
MERCANTILIZACIÓN Y AUTENTICIDAD EN LA FRONTERA URUGUAYO-BRASILEÑA: EL PORTUÑOL EN EL SIGLO XXI
}

\author{
MERCANTILIZAÇÃO E AUTENTICIDADE NA \\ FRONTEIRA URUGUAIO-BRASILEIRA: \\ O PORTUNHOL NO SÉCULO XXI
}

Pablo Albertoni*

\begin{abstract}
RESUMEN
La situación sociolingüística de la frontera uruguayo-brasileña ha sido objeto de regulación por parte del Estado uruguayo desde finales del siglo XIX. A lo largo del siglo XX, se implementaron distintas políticas públicas, en particular educativas, para erradicar el portugués y su variedad dialectal, el portuñol. Con el impulso de los acuerdos político-lingüísticos asumidos con el MERCOSUR a fines del siglo pasado, el portugués comienza a representarse como símbolo de integración regional, en contradicción con el tradicional discurso prescriptivo. En el siglo XXI, el proyecto liderado por intelectuales y artistas de postular al portuñol como patrimonio cultural inmaterial de Uruguay ante UNESCO, en el contexto de una creciente producción y difusión de arte en portuñol, modifica el estatus de este recurso periférico tradicionalmente estigmatizado y asociado a las clases subordinadas de la sociedad fronteriza. La patrimonialización reconfigura procesos de inclusión y exclusión, al movilizar a los hablantes de la periferia socioeconómica para garantizar la autenticidad del portuñol. Por un lado, las estrategias que los activistas desarrollan para involucrar a los hablantes auténticos dan cuenta de los distintos portuñoles en circulación, en disputa, quiénes les atribuyen valor, quiénes se benefician y quiénes padecen estas dinámicas (cf. HELLER, 2011). Por otro, la consolidación de un nicho de mercado para la producción artística en portuñol tensiona el delicado equilibrio entre autenticidad y mercantilización, requisito para asegurar el valor de lucro de repertorios estigmatizados en la nueva economía globalizada.

Palabras-clave: portuñol; patrimonio cultural inmaterial; mercantilización lingüística, autenticidad.
\end{abstract}

\section{RESUMO}

A situação sociolinguística da fronteira uruguaio-brasileira está sujeita à regulamentação do Estado uruguaio desde o final do século XIX. Ao longo do século XX, diferentes políticas públicas, principalmente educacionais, foram implementadas para erradicar o português e a sua variedade dialetal, o portuñol. Com o impulso dos acordos político-linguísticos assumidos com o MERCOSUL no final do século passado, o português passa a ser representado como símbolo da integração regional, em contradição com o discurso prescritivo tradicional. No século XXI, o projeto liderado por intelectuais e artistas para nomear o portuñol perante a UNESCO como patrimônio cultural imaterial do Uruguai, no contexto de uma crescente produção e difusão da arte em portuñol, modifica o status deste recurso periférico tradicionalmente estigmatizado e associado às classes subordinadas da sociedade de fronteira. A patrimonialização reconfigura processos de inclusão e exclusão, ao mobilizar falantes da periferia socioeconômica para garantir a autenticidade do portuñol. Por um lado, as estratégias que os ativistas desenvolvem para engajar aos falantes autênticos dão conta dos diferentes portuñois em circulação, em disputa, quem lhes atribui valores, quem se beneficia e quem sofre com essas dinâmicas (cf. HELLER, 2011). Por outro lado, a consolidação de um nicho de mercado para a produção artística em portuñol sublinha o delicado equilíbrio entre autenticidade e mercantilização, requisito para garantir o valor de lucro de repertórios estigmatizados na nova economia globalizada.

Palavras-chave: portunhol; patrimônio cultural imaterial; mercantilização linguística, autenticidade.

\section{INTRODUCCIÓN}

En este trabajo discuto la mercantilización del llamado portuñol a partir de la iniciativa de un grupo de intelectuales y artistas de la frontera uruguayo-brasileña de postular a esta variedad como patrimonio cultural inmaterial ante UNESCO, en el contexto de una creciente producción artística en y sobre el portuñol. Estas acciones reconfiguran el tradicional estatus del portuñol como recurso estigmatizado dentro del repertorio lingüístico fronterizo y movilizan la discusión sobre quiénes son los hablantes "auténticos" de esta variedad, representados como aquellos que adquirieron el portuñol en el hogar como "lengua materna". Estos hablantes, tradicionalmente pertenecientes a grupos dominados dentro del espacio social, no se han sumado espontáneamente a los espacios de reivindicación, pero su involucramiento resulta fundamental para garantizar la autenticidad del recurso lingüístico patrimonializado.

\footnotetext{
* Universidad de la República, Montevideo, Uruguay. pablo.albertoni@fhce.edu.uy

Orcid: https://orcid.org/0000-0002-9728-100X
} 
La importancia del valor de autenticidad del portuñol responde a la demanda de un mercado capaz de mercantilizar repertorios tradicionalmente estigmatizados y convertirlos en objeto de lucro.

La iniciativa de postular al portuñol como patrimonio cultural inmaterial es un ejemplo de cómo algunos grupos deciden intervenir en la gestión de los recursos lingüísticos, generando dinámicas de disputa en torno a quiénes tienen la autoridad para gestionar y atribuirle valor a estos recursos (HELLER, 2011). Una de esas disputas gira en torno a la propia denominación del recurso: mientras popularmente se lo ha conocido como bayano, carimbao, misturado, brasilero o portuñol, la academia, como se verá, ha preferido denominaciones que se ajustan a las perspectivas teóricas de los investigadores como dialecto fronterizo, dialectos portugueses del Uruguay, portugués uruguayo o portugués del Uruguay (cf. BARRIOS, 2014 para una revisión crítica de las denominaciones académicas). En este trabajo elijo el nombre portuñol porque es la denominación usada por quienes proponen la patrimonialización y entiendo que es la más adecuada para hablar de ese tema.

\section{IDEOLOGÍAS LINGÜÍSTICAS Y LA NUEVA ECONOMÍA GLOBALIZADA: DEL CENTRO A LA PERIFERIA}

Las ideologías lingüísticas son un concepto en continuo desarrollo desde su emergencia a fines del siglo XX. Una definición clásica es la de Woolard (2012 [1998], p. 19), que las caracteriza como "representaciones, sean explícitas o implícitas, que interpretan la relación entre la lengua y los seres humanos en el mundo social", a la vez que señala la diversidad de perspectivas que podría asumir la investigación sobre esa intersección: cuestiones de etnicidad, nacionalismo, actitudes, planificación o historiografía lingüística, son algunos ejemplos. Una concepción similar es la que plantea Kroskrity (2004, p. 501) al caracterizar las ideologías lingüísticas como un "concepto clúster"1 que incluye diversos fenómenos individuales o grupales, como su rol mediador en la experiencia de los individuos o su función en la construcción de identidades sociales. Más recientemente Cavanaugh (2020, p. 52) propone que las ideologías lingüísticas son "creencias y actitudes que conforman las relaciones de los hablantes con sus propias lenguas y con las de los otros, mediando entre la práctica social del lenguaje y las estructuras socioeconómicas y políticas dentro de las que se producen". Ya sean entendidas como representaciones, creencias o actitudes, las ideologías lingüísticas resaltan el rol crucial que cumple el lenguaje en la producción y reproducción de las estructuras sociales.

En el contexto de la nueva economía globalizada existe cierto consenso en que la intensificación en el flujo de personas, capitales e información altera los procesos de producción y reproducción de estas estructuras. Como resulta evidente a partir de una mirada histórica, los repertorios lingüísticos que median y construyen estos procesos pueden adquirir el valor de recursos económicos y cumplir un rol legitimador de las diferencias e inequidades sociales (HELLER $;$ MCELHINNY, 2017). Heller (2003) observa un movimiento en la valoración del lenguaje, desde un atributo que identifica a los miembros de un grupo hacia una habilidad técnica, medida y evaluada. La creciente valoración del lenguaje como recurso económico da lugar a los procesos de mercantilización del lenguaje que, de acuerdo a Heller (2010, p. 107), "confronta monolingüismo con multilingüismo, estandarización con variabilidad, y prestigio con autenticidad en un mercado donde los recursos lingüísticos han adquirido relevancia y valor". Heller y Duchêne $(2012,2016)$ señalan que, junto con los discursos tradicionales de la modernidad que conciben a las lenguas como un recurso político o cultural que identifica a la nación, desde la década de 1990, se suma un discurso que presenta a las lenguas como un valor agregado que favorece el desarrollo económico de las comunidades y las personas que lo poseen. Los autores denominan a este último tipo de discurso lucro en relación con el primer tipo, que denominan orgullo: ambos constituyen "los términos clave empleados para justificar la importancia de las variedades lingüísticas y convencer a la gente de hablarlas, aprenderlas, apoyarlas o pagar para escucharlas hablar" (HELLER; DUCHÊNE, 2012, p. 3-4).

La expansión de capitales (en particular en el sector terciario de la economía) requiere el dominio de un número cada vez mayor de aquellos recursos lingüísticos que ocupan un lugar central en la nueva economía globalizada, mientras que los recursos más periféricos pueden convertirse en signos de autenticidad, ante la necesidad de apertura de nuevos nichos de mercado (HELLER, 2010). La posibilidad de manipular la autenticidad responde a que esta es fundamentalmente un sistema de valores capaz de fijar identidades personales, sociales y culturales que se materializa en prácticas discursivas (COUPLAND, 2003, 2010). Pietikäinen et al. (2016) distinguen entre autenticidades tradicionales, asociadas a una visión esencialista de lo auténtico, y autenticidades transaccionales, que dan cuenta

1. A pedido de los editores invitados, traduje las citas cuando no había traducción publicada. 
de formas más flexibles de autenticidad, como la escenificación de prácticas auténticas de lenguas patrimoniales con fines turísticos (COUPLAND; COUPLAND 2014), una estrategia que da cuenta de procesos de mercantilización de la autenticidad (HELLER, 2014).

En el contexto de globalización, Woolard (2007) señala que la autoridad lingüística se sostiene a través de dos sistemas ideológicos: autenticidad y anonimato. El primero sitúa el valor de una lengua en su localidad, asociada a una comunidad concreta y arraigada a un territorio, el segundo promueve un valor de neutralidad, universalmente disponible. Así, las lenguas minoritarias y variedades no estándares se vinculan con la autenticidad y las lenguas hegemónicas con el anonimato. Por otra parte, las lenguas anónimas pueden ser adquiridas por cualquier persona que tenga intención de hacerlo (en un contexto formal, por ejemplo), pero las auténticas deben ser adquiridas en contextos naturales para consagrarse como tales (WOOLARD, 2016). La transgresión de estos modos de adquisición pone en el debate cuáles son los hablantes que tienen la autoridad para erigirse como bablantes auténticos de las variedades minoritarias y cuál es el estatus identitario de los nuevos bablantes que las adquieren en contextos formales (JAFFE, 2015).

Wang et al. (2014) presentan algunas estrategias de visibilización que desarrollan los grupos que se encuentran en los márgenes de la globalización: el uso de tecnologías de la comunicación para que recursos lingüísticos locales accedan al mainstream, el turismo cultural destinado a consumidores ávidos de descubrir experiencias auténticas en las que las variedades locales juegan un papel crucial y, finalmente, las estrategias para convertir los repertorios marginales en objeto de orgullo e identidad local:

los hablantes de estas lenguas locales se involucran en proyectos de conservación, codificación y revitalización lingüística. Muchos de estos proyectos son financiados por gobiernos regionales y legitimados por convenciones internacionales sobre la preservación del patrimonio cultural inmaterial (o intangible). (p. 36)

Estas estrategias pueden convertira los espacios periféricos en centros de normatividad, algo que tradicionalmente se asocia con espacios centrales de poder político, económico y social (PIETIKÄINEN; KELLY-HOLMES, 2013). Los movimientos de reivindicación de minorías lingüísticas se movilizan para asociar sus repertorios con valores de autenticidad, lo que expone la capacidad de agentividad de grupos periféricos para posicionarse lingüísticamente en el contexto de la nueva economía globalizada (HELLER, 2014). Ante la creciente posibilidad de "comercializar 'la periferia"" estos movimientos generan disputas por la autoridad sobre los recursos lingüísticos movilizados, en particular entre los tradicionales hablantes auténticos o nativos y los expertos o burócratas (PIETIKÄINEN et al., 2016, p. 29).

Cuando las disputas por la autoridad se dan en torno a recursos lingüísticos estigmatizados, cuyos hablantes pertenecen a grupos dominados, pueden reconfigurarse las relaciones entre diferentes posiciones de clase. Para Bourdieu (2006), las posiciones de clase en el espacio social están determinadas por el capital objetivado (bienes económicos o culturales) y por el capital incorporado (en forma de babitus de clase) que se expresan como gustos de clase. Dentro del mercado lingüístico, aquellos que poseen el babitus de clase dominante son quienes tienen mayor facilidad para acceder a la lengua legítima, cuyo dominio es un requisito excluyente para ocupar posiciones de clase dominante. Inversamente, quienes no tengan acceso a la lengua legítima verán comprometida la posibilidad de ocupar posiciones dominantes en el espacio social (BOURDIEU, 2008). De acuerdo a Block (2017), existen cinco dimensiones interrelacionadas que pueden funcionar como indicio de clase: recursos económicos (propiedades, ingresos, ahorro), recursos socioculturales (educación, ocupación, contactos), conductas (consumo, pasatiempos), condiciones de vida (salud, barrio de residencia) y condiciones espaciales (tipo y dimensión de la vivienda). Estas dimensiones serán recuperadas durante este artículo para señalar posicionamientos de clase en los datos analizados.

Los datos incluyen el libro Jodido Bushinshe. Del bablar al ser. Portuñol como patrimonio cultural inmaterial (DA ROSA, 2017a), que, según su coordinador, "es en sí mismo el primer argumento formal para la defensa de la postulación de las expresiones artísticas y usos sociales del Portuñol como PCI [patrimonio cultural inmaterial]" (DA ROSA 2017b, p. 11). Además, analizo una entrevista que realicé a un integrante del colectivo Jodido Busbinshe. La entrevista, que tiene una duración de 90 minutos, se realizó en 2018 durante un congreso del que participé en la ciudad de Rivera, en la frontera norte con Brasil. En esa ocasión invité al entrevistado a escuchar mi comunicación que trataba sobre el proceso de patrimonialización (publicada luego como ALBERTONI, 2018). El entrevistado, oriundo de Rivera y con formación terciaria, asistió a mi presentación y accedió a realizar la entrevista a continuación, en la que hablamos 
sobre mi comunicación, la historia del proyecto Jodido Busbinshe, sus inicios, las actividades realizadas, los proyectos futuros y los objetivos que persigue la patrimonialización.

Durante 2015 y 2016 participé como observador en algunas de las actividades de Jodido Busbinshe, junto con colegas que investigan desde hace décadas la situación sociolingüística de la frontera y fueron convocados a participar. Además de este vínculo académico, parte de mi familia vive en la ciudad de Rivera, por lo que durante las reuniones familiares no he podido evitar observar las prácticas lingüísticas cotidianas, aunque estas observaciones no forman parte de este trabajo.

De aquí en mas, el artículo se organiza de la siguiente forma: en el próximo apartado presento una breve revisión de la literatura académica sobre el repertorio lingüístico de la frontera uruguayo-brasileña, indicadores socioeconómicos de la región noreste de Uruguay y presento algunos aspectos de la producción artística en portuñol. En un segundo apartado realizo una contextualización general del concepto de patrimonio cultural inmaterial a partir de varios documentos de UNESCO, que incluyen la Convención para la Salvaguardia del Patrimonio Cultural Inmaterial y otros textos referidos a la normativa del proceso de patrimonialización. El tercer apartado incluye una reseña histórica de las actividades del proyecto Jodido Bushinshe. En los siguientes apartados discuto las ideologías lingüísticas sobre el repertorio fronterizo que se manifiestan en el proceso de postulación del portuñol como patrimonio cultural inmaterial en Uruguay, en el contexto de una creciente producción de arte en portuñol. Finalmente, realizo unas breves consideraciones finales.

\section{LA FRONTERA URUGUAYO-BRASILEÑA: UNA RETROSPECTIVA HACIA EL FUTURO}

El territorio que actualmente ocupa Uruguay fue durante el período colonial una región en disputa entre España y Portugal. La entonces denominada Banda Oriental constituía una región periférica en la lucha imperial. La ciudad de Colonia del Sacramento en la región suroeste de Uruguay es un ejemplo de esas tensiones: fundada por portugueses en 1680, pasó sucesivamente a manos españolas y portugueses hasta el Tratado de San Ildefonso en 1777, que la consagró como territorio español. Aún con la ciudad de Montevideo ya fundada y el proceso independentista en marcha, la región siguió alternando entre españoles y portugueses hasta la independencia de Uruguay en el primer tercio del siglo XIX (REYES ABADIE; BRUSCHERA; MELONIO, 1974).

Luego de su independencia, la lucha entre imperios continuó en territorio uruguayo entre intereses políticos locales (que podrían alinearse en la dicotomía ciudad-campo) hasta mediados del siglo XIX. El entonces naciente Estado comenzó a organizar lo que había quedado entre sus fronteras y a construir un sentimiento de nacionalidad aún difuso. La lucha entre españoles y portugueses había dejado su huella lingüística en el territorio: el norte de Uruguay se constituyó como una zona periférica, habitado por poderosos hacendados brasileños/portugueses, mientras que en el sur, con Montevideo como capital y centro de poder, había una fuerte presencia de inmigrantes españoles e italianos. En el sur primaba un sentimiento de herencia española y la convicción de que Brasil era una amenaza para la soberanía nacional (MENA SEGARRA, 1969).

Mientras Uruguay intentaba encontrar su espíritu nacional, a fines del siglo XIX ocurrió el primer hito políticolingüístico en la historia uruguaya con la aprobación del Decreto-Ley de Educación Común de 1877. En esta ley se extendió la educación pública a todo el territorio nacional, que debía realizarse en el "idioma nacional". Sin necesidad de aclarar cuál idioma era ese, la práctica estableció al español como la única lengua de instrucción. El creador del decreto-ley, José Pedro Varela, señalaba entonces la importancia de llevar el español al norte del país para extender el sentimiento nacional en una región que representaba una amenaza a la soberanía nacional (BARRIOS, 2013, OROÑO, 2016a).

Cuarenta años después de la aprobación de la Ley de Educación Común, la preocupación por el portugués seguía siendo un debate a nivel de la educación. En 1907 se realizó el Cuarto Congreso de Inspectores Departamentales de Instrucción Primaria con representantes de todo el país. En esa instancia, mientras algunos inspectores departamentales planteaban que el portugués en el norte del país era una amenaza para la identidad nacional, otros más moderados resaltaban la contribución económica que los hacendados brasileños allí instalados realizaban para la construcción de escuelas públicas (OROÑO, 2016b, 2017).

En la historiografía lingüística uruguaya, los estudios académicos sobre la situación sociolingüística de la frontera comenzaron con José Pedro Rona, que en 1959 propuso una primera denominación técnica para esa 
variedad: dialecto fronterizo. A partir de las investigaciones de Rona, la consejera de Enseñanza Primaria y Normal Eloísa García Etchegoyen propuso un proyecto experimental para evaluar la pertinencia de implementar un programa de educación bilingüe en escuelas de frontera (GARCÍA ETCHEGOYEN, 1967). El proyecto generó una gran polémica entre legisladores y periodistas que se mostraron indignados ante lo que entendían era una propuesta con escaso rigor científico y que atentaba contra la soberanía nacional (FUSTES, 2016). El proyecto experimental de García Etchegoyen nunca llegó a implementarse.

Entre 1973 y 1985 se instaló en Uruguay una dictadura cívico-militar. Durante este período la amenaza de lo brasileño (y su correlato lingüístico, el portugués) volvió al debate. Para conmemorar el centenario del primer Congreso Nacional de Inspectores Departamentales de Educación Primaria de 1878, se organizó un nuevo congreso donde la frontera fue un tema central. La amplia cobertura periodística del evento destacó la importancia de la lucha contra el portugués para mantener la soberanía e identidad nacional. El congreso debe entenderse como la estrategia de un gobierno ilegítimo para afirmar su autoridad y la construcción de lo brasileño/portugués como una amenaza de la que Uruguay necesitaba ser protegido (BARRIOS; PUGLIESE, 2005, BARRIOS 2015, 2019).

Durante la dictadura militar la investigación académica sobre la situación sociolingüística de frontera continuó adelante. En 1973 Adolfo Elizaincín caracteriza la zona fronteriza como diglósica, con el fronterizo como variedad baja y señala que "solo los niveles socioculturales bajos se presentan como únicamente fronterizo-hablante, desconociendo por completo el español, sobre todo en las zonas rurales" (ELIZAINCÍN, 1973, p. 4). Hacia finales del período dictatorial se acuña una nueva denominación para la variedad fronteriza: dialectos portugueses del Uruguay (DPU) (ELIZAINCÍN, BEHARES, 1981). Behares (1984) señalaba esquemáticamente el vínculo entre el repertorio lingüístico fronterizo y clase social, que diferenciaba una clase alta monolingüe en español, una clase media con un ideal de comportamiento monolingüe en español, aunque con conocimiento y uso de DPU en el ámbito doméstico, y una clase baja con DPU como primera lengua y español como segunda, adquirida en la educación. El autor señalaba además que en los jóvenes de entonces "se nota un definido interés por el portugués estándar, por el bilingüismo y, en ocasiones, una revaloración de los DPU" (BEHARES 1984, p. 11).

A fines del siglo XX, un segundo hito político-lingüístico relativo al portugués en Uruguay se vincula con la creación del MERCOSUR en 1991. En el ámbito educativo, una de las medidas más importantes en educación lingüística fue la propuesta de enseñar las lenguas oficiales de los países integrantes del bloque. Así, Uruguay comenzó a instrumentar la enseñanza de portugués como lengua adicional con el objetivo de formar una conciencia ciudadana favorable al proceso de integración: los discursos que vinculan al portugués con la integración regional estaban instalados. Barrios (1996) señala la paradoja del sistema educativo uruguayo que comenzó a enseñar la lengua que había representado como amenaza a su soberanía, hecho que se concretó en 1996, cuando se introdujo como optativa en enseñanza media (ANEP, 2008).

La introducción del portugués en la enseñanza pública uruguaya avanzó durante el siglo XXI. A partir de 2003 se implementaron programas bilingües en escuelas primarias fronterizas (BRIAN; BROVETTO; GEYMONAT, 2007, ANEP, 2019a), con el portugués estándar como lengua de instrucción. En 2006 se conformó la Comisión de Políticas Lingüísticas (CPL) en la educación pública, que propuso la enseñanza de dos lenguas extranjeras obligatorias: inglés y portugués, además de una tercera de opción obligatoria, con una propuesta diferencial para la región fronteriza con Brasil (ANEP, 2008). En línea con las investigaciones académicas, para la CPL el portugués del Uruguay (denominación empleada desde entonces por el sistema educativo) "puede considerarse una lengua fronteriza, minoritaria, y de herencia" que ha sido históricamente reprimida por el sistema educativo. La estigmatización "está basada en el desconocimiento de la realidad lingüística local", "supone una ignorancia acerca de la naturaleza y funcionamiento de las lenguas naturales" y "desconoce los beneficios cognitivos y sociales del bilingüismo" (ANEP, 2008, p. 67).

En 2008 se aprobó la Ley General de Educación que dentro del artículo 40 reconoce al portugués del Uruguay como una de las lenguas maternas del país:

La educación lingüística tendrá como propósito el desarrollo de las competencias comunicativas de las personas, el dominio de la lengua escrita, el respeto de las variedades lingüísticas, la reflexión sobre la lengua, la consideración de las diferentes lenguas maternas existentes en el país (español del Uruguay, portugués del Uruguay, lengua de señas uruguaya) y la formación plurilingüe a través de la enseñanza de segundas lenguas y lenguas extranjeras. (MINISTERIO DE EDUCACIÓN Y CULTURA, 2009, p. 249A)

Desde 2016 comenzó a elaborarse el Marco Curricular de Referencia Nacional, del que hasta el momento se han editado algunos documentos. Uno de ellos contiene las progresiones de aprendizaje para el dominio lingüístico- 
discursivo y propone progresiones para el español y la lengua de señas uruguaya. Con respecto al portugués se menciona que "por el momento no se incluye un tercer escenario para los hablantes de portugués del Uruguay" (ANEP, 2019b, p. 19), hecho que plantea algunas dudas acerca de su futura inclusión. En efecto, las prácticas lingüísticas que transitan entre el español y el portugués continúan siendo marginalizadas en el sistema educativo, a pesar de la implementación de los programas bilingües en escuelas de frontera (BORTOLINI; GARCEZ; SCHLATTER, 2015).

En este contexto de relativo reconocimiento de los derechos de los hablantes de portugués, con propuestas de enseñanza en la educación pública, ha habido un importante crecimiento en la producción y difusión de música, literatura y teatro en portuñol, muchas veces abordando temas de la compleja realidad socioeconómica de la frontera. En efecto, la región noreste de Uruguay (que incluye los departamentos de Rivera, Tacuarembó y Cerro Largo) posee el índice de desarrollo humano más bajo del país. Según datos de 2019 del Observatorio Territorio Uruguay de la Oficina de Planeamiento y Presupuesto ${ }^{2}$, la región noreste tiene el mayor porcentaje de hogares en situación de pobreza de Uruguay $(7,4 \%$ frente a 5,9\% del promedio país). A nivel de trabajo, si bien el desempleo era menor que la media país (6,5\% frente a 8,3\%), la tasa de informalidad entre las personas ocupadas superaba ampliamente el promedio país ( $40,5 \%$ frente a $24,8 \%)$. Con respecto a la educación, el noreste posee la mayor tasa de analfabetismo $(2,3 \%$, frente a $1,2 \%$ del país) y el menor porcentaje de la población entre 25 y 65 años con educación terciaria $(11,6 \%$ frente a $23,8 \%)$.

La pobreza, las dificultades de integración en el sistema educativo o la falta de trabajo están tematizados en buena parte de la literatura en portuñol, que tiene autores destacados desde mediados del siglo XX, como Agustín Bisio u Olyntho Maria Simões. En las últimas décadas la producción artística se ha incrementado y diversificado. Fabián Severo, cuya vida y obra es objeto de estudio en el ámbito académico (cf. LOPES; SILVA, 2018), es uno de los artistas más populares que producen en portuñol. Su novela "Viralata", escrita en portuñol y ambientada en un barrio pobre de frontera, obtuvo en 2017 el Premio Nacional de Literatura del Ministerio de Educación y Cultura de Uruguay. La novela fue adaptada al teatro y estrenada en 2018 en el Teatro El Galpón de Montevideo, uno de los teatros independientes más populares de la ciudad. Su libro "Noite nu norte" fue recientemente traducido al inglés (SEVERO, 2019) y uno de sus poemas traducidos se publicó en la revista estadounidense The New Yorker (2 de diciembre de 2019).

Otros ejemplos recientes de arte en portuñol o tematizándolo incluyen el estreno en 2020 de la obra "Naturaleza trans" en el Teatro Solís de Montevideo (el principal teatro público de la ciudad) y en el Festival Internacional de Buenos Aires. El espectáculo es protagonizado por actrices transexuales que narran en portuñol sus historias de discriminación en la frontera. También en 2020 se estrenó el documental "Portuñol", de la brasileña Thais Fernandes, que presenta testimonios sobre la realidad sociolingüística en varios puntos de la frontera brasileña. La película se presentó en el Festival de Cine de Gramado, donde obtuvo el premio especial del jurado y el premio del público.

A nivel musical, varios discos editados en Uruguay en los últimos años utilizan el portuñol, además de abordar temas de la sociedad fronteriza en sus canciones: "El alma de Cheroga", de María do Carmo (2011), "Cualquier uno", de Ernesto Díaz (2013), "Misturado", de Chito de Mello (2018), "Memorias del Yaguarí", de Yoni de Mello (2018). Otros artistas como el grupo de cumbia Terremoto o la cantante de hiphop Camila Techeira difunden su música en conciertos o a través de YouTube.

En este breve recorrido histórico, hemos visto que durante el siglo XIX y principios del XX el portugués era hablado, entre otros, por hacendados poderosos en el norte del territorio uruguayo. Durante el siglo XX, la expansión del español a través del sistema educativo y la difusión de una ideología monolingüe y nacionalista por parte del Estado desplazó al portugués del repertorio fronterizo, mientras que el portuñol se desarrolló como un recurso lingüístico periférico usado principalmente por grupos subordinados en la sociedad fronteriza. Desde finales del siglo XX y, en particular, en el siglo XXI la valoración del portuñol parece estar cambiando a través de un movimiento de intelectuales y artistas que producen literatura, música y teatro en y sobre el portuñol, para un mercado que parece estar dispuesto a consumirlo. Esta creciente centralidad del portuñol es impulsada también por el proyecto de declararlo como patrimonio cultural inmaterial ante UNESCO. Para contextualizar la propuesta de patrimonialización, presento a continuación la definición de patrimonio inmaterial y el lugar que UNESCO asigna al lenguaje dentro de esta definición.

2. Disponibles en <https://otu.opp.gub.uy>. Acceso: 21 jun. 2021. 


\title{
3. UNESCO Y EL PATRIMONIO CULTURAL INMATERIAL: INSTITUCIONALIZAR LO AUTÉNTICO
}

La declaración de un bien como patrimonio cultural inmaterial (PCI) se presenta como una estrategia de grupos minoritarios para la protección de prácticas culturales que se consideran amenazadas. Con la aprobación de la Convención para la Salvaguardia del Patrimonio Cultural Inmaterial (CSPCI) de UNESCO en 2003, se conformó un espacio institucionalizado para que las comunidades puedan acceder a un reconocimiento global y a la protección de sus prácticas culturales, siempre que estas cumplan con los requisitos que exige UNESCO.

La CSPCI define el PCI en su artículo segundo como:

\begin{abstract}
los usos, representaciones, expresiones, conocimientos y técnicas -junto con los instrumentos, objetos, artefactos y espacios culturales que les son inherentes- que las comunidades, los grupos y en algunos casos los individuos reconozcan como parte integrante de su patrimonio cultural. Este patrimonio cultural inmaterial, que se transmite de generación en generación, es recreado constantemente por las comunidades y grupos en función de su entorno, su interacción con la naturaleza y su historia, infundiéndoles un sentimiento de identidad y continuidad y contribuyendo así a promover el respeto de la diversidad cultural y la creatividad humana. (UNESCO, 2016, p. 5)
\end{abstract}

Complementando la definición, el documento establece además una lista de los ámbitos en los que el PCI se puede manifestar:

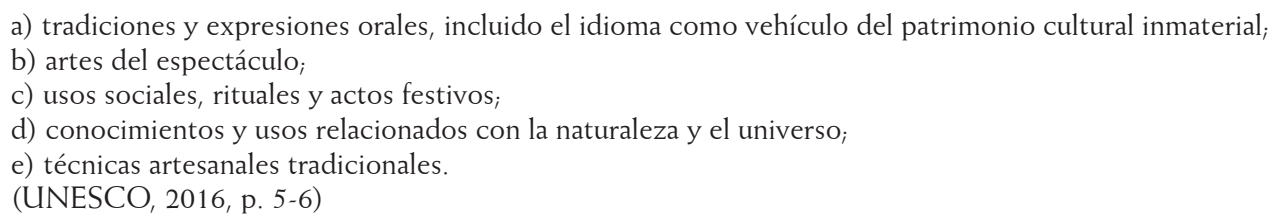

El lenguaje, entendido como "idioma", se incluye dentro de las tradiciones y expresiones orales, aunque solo puede ser patrimonializado como vebículo del PCI. En otro documento sobre la convención, UNESCO establece una distinción entre el lenguaje como sistema lingüístico y como instrumento transmisor de prácticas culturales de apertura: la Convención tampoco incluye el idioma propiamente dicho o como conjunto de reglas (gramática, vocabulario y sintaxis), pero señala que es un vector fundamental de transmisión del patrimonio cultural inmaterial" (UNESCO, 2011a, p. 7).

En una publicación que desarrolla el contenido de los ámbitos en los que puede manifestarse el patrimonio inmaterial (UNESCO, 2011b), se privilegia la protección del lenguaje como instrumento transmisor de prácticas culturales, frente a su revitalización mediante instrumentos normativos (diccionarios, gramáticas) para funcionar en instituciones de poder al servicio del Estado-nación:

La muerte de un idioma conduce inevitablemente a la pérdida definitiva de tradiciones y expresiones orales. No obstante, esas mismas expresiones orales y su recitación en público son las que más contribuyen a salvaguardar un idioma, más que los diccionarios, las gramáticas o las bases de datos. (UNESCO, 2011b, p. 4-5)

De acuerdo a Smeets (2004), el lugar del lenguaje fue ampliamente discutido durante la redacción de la CSPCI debido a que varios países fueron reticentes a incluirlo como bien patrimonializable. En la medida en que los Estados que suscriben la convención tienen que reglamentarla dentro de sus territorios, la inclusión de los "idiomas" significaba un desafío a las lógicas monolingües nacionales. Algunos países crearon sus propios dispositivos de patrimonialización, como el Inventario Nacional de la Diversidad Lingüística ${ }^{3}$ en Brasil, que reconoce más de 200 lenguas de inmigración, indígenas, afro-brasileñas, criollas y de señas (MORELLO, 2012). La postulación del portuñol es el único caso de un recurso lingüístico que se propone como $\mathrm{PCI}$ en Uruguay. A continuación presento las diferentes actividades que se han organizado en el marco de la postulación.

\section{EL PROYECTO JODIDO BUSHINSHE: EL PORTUÑOL EN ESCENA}

Junto con el moderado reconocimiento del portugués del Uruguay en la legislación político-lingüística de Uruguay y con el aumento de la producción artística en portuñol, en 2015 trascendió el proyecto Jodido Bushinshe, que postula

3. Disponible en: <http://portal.iphan.gov.br/indl> Acceso: 20 jun. 2021

4. Bushinshe es una adaptación de bochinche, término presente en español y portugués que significa "ruido", "tumulto", "desorden". Jodido bushinshe podría traducirse entonces como "gran ruido", "gran tumulto" o "gran desorden". 
al portuñol como patrimonio cultural inmaterial de Uruguay. Jodido Bushinshe, es un colectivo integrado de modo más o menos estable por académicos (lingüistas, antropólogos, historiadores), docentes (de enseñanza primaria y secundaria) y artistas (músicos y escritores que utilizan el portuñol para sus creaciones) que residen en la frontera uruguayo-brasileña, mayoritariamente en la ciudad de Rivera. Entre los académicos y docentes que integran el colectivo hay una cantidad similar de hombres y mujeres, mientras que los artistas son hombres en su mayoría.

Entre julio y noviembre de 2015 el colectivo realizó sus primeras actividades bajo el nombre Jodido Bushinshe. Del hablar al ser, una serie de conferencias y presentaciones artísticas con el apoyo de Centros MEC Rivera (oficina regional del Ministerio de Educación y Cultura de Uruguay) y el Centro Universitario de Rivera (sede local de la Universidad de la República). De acuerdo a los organizadores, la actividad tuvo como objetivos generar una "masa crítica colectiva" sobre "cultura de frontera y portuñol como patrimonio inmaterial" y apoyar el "proceso de argumentación de la postulación del Portuñol como Patrimonio Cultural Inmaterial". El público estuvo compuesto por "estudiantes terciarios, profesionales de áreas sociales, intelectuales locales y público en general" ("Proceso de postulación..." 2017, p. 18).

En setiembre de 2015 el diputado riverense Saúl Aristimuño realizó una exposición en el Parlamento uruguayo en la que manifestó su apoyo al proyecto de postulación y la necesidad de reconocer "una riqueza cultural construida a lo largo del tiempo, en una frontera amplia y generosa, desde Rocha hasta Salto y, en especial, en Rivera, la que muchas veces es desconocida y subestimada por el sur" (CÁMARA DE REPRESENTANTES DEL URUGUAY, 1 de setiembre de 2015, p. 20). En diciembre de ese mismo año se realizó un seminario titulado Jodido Bushinshe. Los portuñoles/ Os portunbois, en el que participaron académicos de universidades uruguayas y brasileñas que investigan sobre frontera (UDELAR, Unipampa, UFSM, UFPel) y autoridades del Ministerio de Educación y Cultura de Uruguay, de la Comisión del Patrimonio Cultural de la Nación de Uruguay y del Instituto del Patrimonio Histórico y Artístico Nacional de Brasil. De acuerdo a los organizadores este seminario marcó un cambio en la propuesta de patrimonialización ya que "la patrimonialización de una lengua o dialecto no es viable dadas las definiciones de la Convención de la UNESCO sobre Patrimonio Inmaterial", por lo que fue necesario "seguir el proceso de patrimonialización de los conocimientos, tradiciones y expresiones artísticas transmitidas a través del Portuñol. El Portuñol como medio y no como objetivo" ("Seminario Jodido Bushinshe...", 2017, p. 172-173).

En 2016 se realizó una presentación de Jodido Busbinsbe en la antesala de la Cámara de Diputados del Parlamento uruguayo, organizada por Centro MEC Rivera y el diputado Aristimuño. El evento tuvo como invitados a la investigadora Graciela Barrios y a los escritores Carlos Enrique de Mello y Fabián Severo, este último realizó su presentación en portuñol. En 2017 se publicó el libro Jodido Busbinshe. Del hablar al ser. Portuñol como patrimonio cultural inmaterial (DA ROSA, 2017a), con artículos de varios de los expositores de las actividades de 2015 y que forma parte de los datos analizados en este trabajo.

Además de las conferencias académicas y los espectáculos artísticos, Jodido Bushinshe ha organizado actividades para fomentar la creación y difusión de arte en portuñol. Entre 2017 y 2019 organizó un "Concurso de dramaturgia joven fronteriza" dirigido a jóvenes entre 15 y 30 años residentes en los departamentos uruguayos fronterizos de Rivera, Artigas y Cerro Largo, y en los municipios brasileños de Santana do Livramento, Quaraí y Jaguarão. El concurso, que tuvo tres ediciones hasta el momento y 16 obras presentadas, señala en sus bases que "el jurado valorará especialmente las obras que muestren rasgos característicos de la cultura regional de hoy, y las lenguas que interactúan en nuestra frontera, como rasgo de identidad peculiar de esta región binacional, multicultural y multilingüe" y que es de especial interés "alentar la producción de teatro en portuñol" ${ }^{\prime \prime}$ (subrayado en el original).

Desde 2017 Jodido Busbinshe organiza un evento anual en el marco del Día Internacional de la Lengua Materna promovido por UNESCO que se denomina "Como dizía miña avó". En su edición de 2017 el evento propuso una maratón de lectura de textos en portuñol. En la edición 2019 la propuesta incluyó "Portuñol, Italiano, Árabe, y la convivencia con el Español y el Portugués" (Diario Norte, 21 de febrero de 2019).

La respuesta del Estado uruguayo (que gestiona ante UNESCO las declaraciones de patrimonio) a la postulación ha sido algo tímida. Probablemente el mayor reconocimiento es incluir el proyecto en el libro Saberes compartidos. Proceso de inventario de patrimonio cultural inmaterial de Uruguay (CANNELLA; PICÚN, 2019), publicado por la Comisión para

5. Disponible en: <https://www.gub.uy/ministerio-educacion-cultura/sites/ministerio-educacion-cultura/files/documentos/noticias/bases2019-del-concurso-dramaturgia-fronteriza.pdf> . Acceso: 20 jun. 2021.

6. Disponible en: <https://www.diarionorte.com.uy/cultura/como-dizia-mina-avo-las-lenguas-maternas-de-nuestra-frontera-49759.html > . Acceso: 20 jun. 2021. 
el Patrimonio Cultural de la Nación. El texto recopila diferentes propuestas postuladas como patrimonio cultural inmaterial de Uruguay e incluye entre ellas a las "lenguas de la frontera norte" (p. 123). En la descripción de estas "lenguas" se presenta una breve reseña de investigaciones sobre el repertorio lingüístico fronterizo, junto con poemas de Agustín Bisio y Fabián Severo, además de fotos de "hablantes de portuñol" (p. 129).

En la actualidad existe cierta incertidumbre sobre al futuro de la patrimonialización. Por un lado, entre 2017 y 2019 se discutió en ámbitos parlamentarios un proyecto de ley para crear un Sistema Nacional de Protección del Patrimonio Cultural del Estado para gestionar las declaraciones patrimoniales del país, pero el proyecto fue archivado. Por otro lado, luego del cambio de gobierno en Uruguay en marzo de 2020, se realizó una reestructura del Ministerio de Educación y Cultura que eliminó todas las oficinas de los Centros MEC, institución que apoyó las actividades de Jodido Bushinshe desde 2015.

Más allá de concreción futura, el proceso de postulación ha generado discusiones importantes sobre el estatus del portuñol en el siglo XXI. A continuación recupero algunas de esas discusiones a partir del libro Jodido Busbinshe. Del bablar al ser (DA ROSA, 2017a) y de la entrevista a uno de los integrantes del colectivo que propone la patrimonialización. El entrevistado, nacido en Rivera y en el entorno de los 45 años, es uno de los integrantes más activos del colectivo Jodido Bushinshe. Señala que en su infancia el portuñol no era de uso habitual en su hogar, aunque sí en el intercambio con otros familiares. Durante sus estudios terciarios en Montevideo afirma haberse sentido "discriminado" por los comentarios de sus compañeros sobre su forma de hablar.

\section{EL HABLANTE AUTÉNTICO Y LOS NUEVOS HABLANTES: TERRITORIO DE DISPUTAS}

Uno de los debates en torno a la patrimonialización del portuñol es determinar cuáles son los hablantes que tienen la autoridad para llevar adelante la postulación. La determinación del grupo autorizado para gestionar el patrimonio no es solo un reconocimiento simbólico sino que también implica el derecho a la explotación comercial del recurso, como señala el documento Principios éticos para la salvaguardia del patrimonio cultural inmaterial de UNESCO: "las comunidades, grupos e individuos que crean el PCI deberán beneficiarse de la protección de los intereses morales y materiales resultantes de éste" (UNESCO, 2016, p. 132).

En el libro Jodido Busbinshe. Del bablar al ser se recoge la preocupación por determinar cuál es el grupo de hablantes autorizados:

Un tema no menor es la difícil tarea de determinar cuál es el grupo social portador del patrimonio que nos interesa, como se compone ese grupo, que los une y diferencia de los demás. [...] en el Portuñol no existe un colectivo identificado como tal. [...] por otro lado no hay algo tácito que los diferencie de los demás, ya que la propia construcción cultural personal niega su identidad lingüística. Es una gran masa de hablantes escondida en otra masa mayor aún.

De los profesionales que escriben en este libro muchos de ellos tienen al Portuñol como segunda lengua fruto del contacto social, y quizás alguno posiblemente haya tenido en su más temprana infancia al Portuñol como lengua materna. Entonces, ċeste colectivo de autores es parte del grupo social portador del Portuñol como PCI? Y los artistas que se presentaron en cada velada de este ciclo también lo son? Estas preguntas son claves pues solo dicho grupo social de portuñol-hablantes tendrá la autoridad para reclamar su patrimonialización. (DA ROSA, 2017b, p. 15)

Los activistas cuestionan su autoridad sobre el portuñol que no han adquirido en el hogar. Resulta entonces necesario involucrar a los hablantes de portuñol como "lengua materna", que se representan como los hablantes auténticos, con autoridad y derecho para reclamar la patrimonialización. La ponderación de la adquisición en el hogar reproduce el sistema ideológico de la autenticidad (WOOLARD, 2016) y coloca como pieza clave en la patrimonialización a quienes han sido históricamente ubicados en un lugar subordinado del espacio social (la "masa de hablantes escondida en otra masa mayor aún"). No sorprende entonces que sean los intelectuales y artistas que han decidido hablar o crear en portuñol quienes promuevan la patrimonialización de un recurso lingüístico valorizado para ellos pero que para otros ha sido sinónimo de exclusión. Los nuevos hablantes de portuñol, a diferencia de los nuevos hablantes de otras lenguas minoritarias, no han adquirido la variedad en contextos formales a través de proyectos de revitalización (cf. PIETIKÄINEN et al., 2016, JAFFE, 2015), ya que la estrategia de reivindicación del portuñol no incluye su enseñanza en contextos formales. No obstante, el perfil social de los nuevos hablantes de portuñol es similar al de otros contextos investigados: urbano, educados, de clase media y de mediana edad (O'ROURKE; NANDI, 2019). 
La necesidad de consultar a los hablantes de portuñol "auténticos" ha llevado al colectivo Jodido Busbinshe a diseñar estrategias de acercamiento y consulta a estos hablantes, que, aparentemente, no han adherido espontáneamente a la iniciativa. Para esto proponen una muestra en localidades rurales de frontera durante las fiestas locales (cf. HELLER, 2011). La muestra consiste en una puesta en escena de diversas manifestaciones en portuñol como disparador para la reflexión. Según explica el entrevistado,

el grupo que hacemos el Jodido Bushinshe este año resolvió salir a hablar, dialogar con el portuñolhablante, los que lo tienen como lengua materna para tener de ellos también la opinión y también una cosa como para ir midiendo el efecto de nuestro trabajo. La muestra consta de banners, creo que son ocho, diez donde van a estar impresos textos en portuñol, donde están los clásicos, está Olyntho [María Simões], pero hay escritores actuales, músicos actuales, pero hay desgrabaciones de las recetas y la gente va a ir, va a leerlo. [Hay] un plasma donde vamos a estar proyectando documentales sobre el tema de lengua de frontera, cultura de frontera. Y después lo que va a haber es cuatro computadoras con audio permanente con gente contando cosas en portuñol.

Para conservar el valor auténtico del portuñol patrimonializado, la muestra construye una autenticidad transaccional (PIETIKÄINEN et al., 2016) que pone en evidencia cuáles son los distintos portuñoles en circulación y en disputa: por un lado el portuñol de los músicos y escritores (clásicos y actuales), asociado a las clases sociales favorecidas, y por otro, el de las recetas de cocina y de la "gente contando cosas", probablemente vinculado a la ruralidad y a la clase trabajadora. El público asistente a la muestra, es decir, los hablantes "auténticos" serán entrevistados para determinar

si son conscientes de la importancia de una lengua como parte de su identidad, si la sienten como su identidad, si les da vergüenza, si les da orgullo, si le es indiferente. Hay gente que dice no es ni fu ni fa, hablo así y ya está, hay cosas más importantes. Y empezar a destacar el tema este, justamente como un derecho humano, el de la diversidad cultural, y que ellos puedan reclamar.

La muestra planteada por el equipo de Jodido Bushinshe promueve que un repertorio estigmatizado sea reconfigurado como objeto de orgullo e identidad (WANG et al., 2014), para generar conciencia en los hablantes "auténticos" sobre la defensa de su portuñol, a pesar que algunos de ellos puedan considerar que "hay cosas más importantes" que reflexionar sobre su forma de hablar. Si la propuesta de patrimonialización resulta exitosa, el "hablante auténtico" de portuñol puede enfrentarse a la contradicción de obtener un beneficio material por su valor de autenticidad, y, a la vez, sufrir discriminación por usar un recurso lingüístico estigmatizado.

Si bien los beneficios que obtendrán los hablantes auténticos a partir de la patrimonialización del portuñol no resultan evidentes, el esfuerzo que realizan los activistas en sostener el proceso de patrimonialización y desarrollar estrategias para "dialogar con el portuñolhablante" sugiere que el beneficio para ellos es más claro. Sobre eso propongo discutir en el siguiente apartado.

\section{LA MERCANTILIZACIÓN DE LA AUTENTICIDAD: PORQUE EL MERCADO LO PIDE}

La postulación del portuñol como patrimonio cultural inmaterial surge en el contexto de una creciente producción artística en y sobre el portuñol. Como ya se señaló, el proyecto original de patrimonializar el portuñol como "lengua" tuvo que modificarse para cumplir con las exigencias de UNESCO, que impide que una lengua pueda patrimonializarse per se. El nuevo objeto a patrimonializar, "los conocimientos, tradiciones y expresiones artísticas transmitidas a través del Portuñol" ("Seminario Jodido Bushinshe...", 2017, p. 172-173), ubica a la producción artística en un lugar central del proyecto.

En efecto, en el libro Jodido Bushinshe. Del hablar al ser se señala que uno de los objetivos de la patrimonialización es "robustecer las redes de artistas del Portuñol en torno a una resistencia lingüística que luche contra la segregación y evite la espectacularización (el estar de moda) de su propia identidad" (DA ROSA, 2017b, p. 15). La producción artística en portuñol busca resistir la minorización que históricamente han padecido sus hablantes, manteniendo el delicado equilibrio entre la autenticidad de "su propia identidad" y los peligros de su mercantilización, expresados en la cautela frente a la posibilidad de "estar de moda".

El proceso de "espectacularización" de la creación artística en portuñol, no obstante, parece ya haber comenzado si tenemos en cuenta la creciente producción de música, literatura y teatro ya mencionada. La difusión de los artistas que producen en portuñol y la ampliación del mercado para sus obras es uno de los objetivos de la patrimonialización que, según el entrevistado, es un mercado aún desconocido para los montevideanos:

Lo otro era si, lisa y llanamente, visibilizar la producción artística local, que tiene su mercado acá muy pequeño, pero que le falta todavía ir mucho más allá. Quien tiene las puertas del mercado de una manera abierto es Ernesto Díaz, es Fabián [Severo] y uno o dos 
más, pero no tanto como ellos. Lo que hacen bien Ernesto y Fabián es que siempre que hacen algo grande llevan a los demás, llevan al Chito [de Mello] al Yoni [de Mello], llevan a otro. Poder generar también una visibilización por parte del Estado, en un principio pero después que se volviera también autónomo. Algún sello discográfico de la frontera o alguna plataforma por lo menos donde vos pudieras tener toda esa cultura. Siempre le digo a los montevideanos: [...] ustedes tienen la mitad de la oferta cultural del país. La otra mitad que es enorme, que es enorme en variedad, se les escapa. Entonces hay un mercado, el mercado del sur, hablo de mercado para usar el concepto de mercado justamente, que desconocen todo esto, que tiene otra riqueza.

La creación de un nicho de mercado para las producciones artísticas en portuñol propone un discurso que moviliza su potencial valor de lucro (HELLER; DUCHÊNE, 2012), algo ciertamente novedoso para el caso del portuñol. El valor de lucro se refuerza con la mención a la expansión comercial (hacia "el mercado del sur") y sus potenciales consumidores ("los montevideanos"). Desde este punto de vista, la patrimonialización puede entenderse como un proceso de mercantilización mediante el cual un recurso periférico como el portuñol se valoriza por su capacidad de expresar autenticidad ante mercados que consumen lo auténtico como un valor agregado (HELLER, 2010). La discusión sobre el hablante auténtico presentada en la sección anterior no parece relevante en este caso. Los nuevos mercados acceden a un portuñol, distinto al de aquellos hablantes "auténticos" que los activistas buscan involucrar en el proyecto de patrimonialización. Como sostiene Heller (2014), los procesos de mercantilización de repertorios minoritarios extienden y diversifican la definición de autenticidad: mientras el límite que señala el valor auténtico de un producto se mantenga (en este caso, cualquier portuñol), las características del contenido (en este caso, el portuñol del hablante auténtico) ocupa un lugar secundario para el consumidor.

La importancia de mantener el valor auténtico del portuñol en su expansión mercantil implica el cuidado de no equipararlo con recursos más abiertamente prestigiosos del repertorio local, asociados a las clases dominantes y a un sistema ideológico del anonimato (WOOLARD, 2007, 2016): en este caso el español y el portugués estandarizados, como señala el entrevistado,

no queremos que [el portuñol] [...] sea una lengua más de la nación. Que no aparezca en Uruguay se habla español y portuñol, no lo queremos, no queremos estandarizarla. [...] Yo respeto mucho a los que producen en portuñol, de que sienten también eso, de que le quitaría lo silvestre, lo autónomo que tiene del Estado, lo contrabandista que es la cultura de frontera, ¿no?

Para mantener el valor de autenticidad es preciso mantenerse al margen del Estado y no ser parte del discurso identitario de la nación. Los artistas parecen ser conscientes que el nicho de mercado para sus creaciones en portuñol depende del mantenimiento del valor de autenticidad del recurso lingüístico.

\section{CONSIDERACIONES FINALES}

La postulación del portuñol como patrimonio cultural inmaterial ante UNESCO, en el contexto de la creciente producción y difusión de arte en portuñol, moviliza una reconfiguración del estatus subordinado tradicionalmente asociado al portuñol en la frontera uruguayo-brasileña. La necesidad de cumplir con las directivas que establece UNESCO para los bienes a patrimonializar, ha generado disputas sobre quién tiene la autoridad para proponer la patrimonialización y para beneficiarse materialmente de ella. En la medida que UNESCO define el patrimonio siguiendo una ideología de la autenticidad, los únicos autorizados a llevar adelante el proceso son aquellos hablantes que adquirieron la lengua en el hogar, generalmente ubicados en una posición dominada dentro del espacio social fronterizo.

El grupo de intelectuales y artistas que llevan adelante la iniciativa se ven así obligados a recurrir a los hablantes más "auténticos" para involucrarlos en la patrimonialización, aunque estos últimos no parecen interesados en la distinción de UNESCO. La patrimonialización reconfigura procesos de inclusión y exclusión al movilizar hablantes de la periferia socioeconómica para garantizar la autenticidad del portuñol. Las estrategias que los activistas desarrollan para involucrar a los hablantes auténticos dan cuenta de los distintos portuñoles en circulación, en disputa, quiénes les atribuyen valor, quiénes se benefician y quiénes padecen estas dinámicas (cf. HELLER, 2011).

Mientras que en el siglo XXI el portuñol auténtico sigue sin ofrecer un beneficio de lucro para quien lo domina, el portuñol de la producción artística parece haber encontrado un nicho de mercado. La disputa sobre la autenticidad también es una preocupación para los artistas que producen en portuñol, quienes parecen entender que el futuro del nicho de mercado para sus producciones está en el mantenimiento del delicado equilibrio entre autenticidad y 
mercantilización, requisito para que repertorios lingüísticos estigmatizados puedan mercantilizarse en el contexto de la nueva economía globalizada.

\section{REFERENCIAS}

ALBERTONI, P. (2018). Autenticidad y patrimonio: el proceso de postulación del portuñol como patrimonio cultural inmaterial. In: Acevedo, F.; Nossar, K. (eds.). Educación y Sociolingüística. Montevideo: CUR/UDELAR, 179-201.

ANEP (2008). Documentos de la Comisión de políticas lingüísticas en la educación pública. Montevideo: ANEP/CoDiCen.

ANEP (2019a). Departamento de segundas lenguas y lenguas extranjeras. Publicación $N^{0}$ 1. Montevideo: ANEP. Disponible en: https://www.ceip.edu.uy/documentos/2020/segundaslenguas/revista/RevistaDL2LE_N1.pdf. Acceso: 27 feb. 2021.

ANEP (2019b). MCRN. Desarrollo del pensamiento cultural y sus mediaciones. Dominio lingüístico-discursivo. Progresiones de aprendizaje. Montevideo: ANEP. Disponible en: https://mcrn.anep.edu.uy/sites/default/files/MCRN\%203\%202019\%20WEB.pdf. Acceso: 27 feb. 2021

BARRIOS, G. (1996). Planificación lingüística e integración regional: el Uruguay y la zona de frontera. In: Trindade, A. y Behares, L. (orgs.), Fronteiras, educaçao, integração. Santa María: Pallotti, p. 83-110.

BARRIOS, G. (2013). Language diversity and national unity in the history of Uruguay. In: Del Valle, J. (ed.), A political History of Spanish: The making of a language. Nueva York: Cambridge University Press, p. 197-211.

BARRIOS, G. (2014). La denominación de variedades lingüísticas en situaciones de contacto: dialecto fronterizo, DPU, portugués uruguayo, portugués fronterizo o portuñol. In: Hipperdinger, Y. (comp.), Lenguas: conceptos y contactos. Bahía Blanca: Editorial de la Universidad Nacional del Sur, p. 77-105.

BARRIOS, G. (2015). Política lingüística y dictadura militar en Uruguay (1973-1985): los informes institucionales sobre la situación lingüística fronteriza. Estudios de linguiística del español, 36, p. 527-557.

BARRIOS, G. (2019). La prensa escrita como instrumento de adoctrinamiento político-lingüístico durante la dictadura uruguaya (1973-1985). In: Marimón Llorca, C. y Santamaría Pérez, M. I. (eds.), Ideologías sobre la lengua y medios de comunicación escritos. El caso del español. Berlín: Peter Lang, p. 35-55.

BARRIOS, G.; PUGLIESE, L. (2005). Política lingüística y dictadura militar: las campañas de defensa de la lengua. In: Marchesi, A.; Markarián, V.; Rico, A.; Yaffé, J. (comps.), El presente de la dictadura. Estudios y reflexiones a 30 años del golpe de Estado en Uruguay. Montevideo: Trilce, p. 156-168.

BEHARES, L. (1984). Planificación lingiística y educación en la frontera uruguaya con Brasil. Montevideo: Instituto Interamericano del Niño.

BLOCK, D. (2017). Social class in migration, identity and language research. In: Canagarajah, S. (ed.), The Routledge Handbook of migration and language. Nueva York: Routledge, p. 133-148.

BORTOLINI, L.; GARCEZ, P. M.; SCHLATTER, M. (2015). Language practices and identities in transit: Spanish and Portuguese in everyday life in a Uruguayan school community near the border with Brazil. In: Moita Lopes, P. (org.), Global Portuguese: linguistic ideologies in late modernity. Nueva York: Routledge, p. 163-184.

BOURDIEU, P. (2006). A distinção: crítica social do julgamento. Porto Alegre: Zouk.

BOURDIEU, P. (2008). A economia das trocas lingüísticas. San Pablo: EDUSP.

BRIAN, N.; BROVETTO, C.; GEYMONAT, J. (comps.) (2007). Portugués del Uruguay y educación bilingüie. Montevideo: ANEPCEP. 
CÁMARA DE REPRESENTANTES DEL URUGUAY (1 de setiembre de 2015). Diario de sesiones 3988. XLVIII Legislatura. [Intervención de Saúl Aristimuño].

CANNELLA, L.; PICÚN, O. (2019). Saberes compartidos. Proceso de inventario de patrimonio cultural inmaterial del Uruguay. Montevideo: Comisión del Patrimonio Cultural de la Nación.

CAVANAUGH, J. (2020). Language ideology revisited. International Journal of the Sociology of Language, 263, p. 51-57.

COUPLAND, N. (2003). Sociolinguistics authenticities. Journal of sociolinguistics, 7, 3, p. 417-431.

COUPLAND, N. (2010). The authentic speaker and the speech community. In: Llamas, C.; Watt, D. (eds.), Language and identities. Edinburgo: Edinburgh University Press, p. 99-112.

COUPLAND, N.; COUPLAND, B. (2014). The authenticating discourses of mining heritage tourism in Cornwall and Wales. Journal of sociolinguistics, 18, 4, p. 495-517.

DA ROSA, E. (comp.) (2017a). Jodido Bushinshe. Del hablar al ser. Portuñol como patrimonio cultural inmaterial. Montevideo: Centros MEC.

DA ROSA, E. (2017b). A modo de presentación. In: Da Rosa, E. (comp.), Jodido Bushinshe. Del hablar al ser. Portuñol como patrimonio cultural inmaterial. Montevideo: Centros MEC, p. 9-15.

ELIZAINCÍN, A. (1973). Algunos aspectos de la sociolingüística del dialecto fronterizo. Montevideo: Universidad de la República.

ELIZAINCÍN, A.; BEHARES, L. E. (1981). Variabilidad morfosintáctica de los dialectos portugueses del Uruguay. Boletín de Filología [Santiago de Chile], 31, 1, p. 401-417.

FUSTES, J. M. (2016). Las concepciones sobre la enseñanza de la lengua en la escena académica uruguaya entre 1920 y 1970. Tesis de maestría. Montevideo: Facultad de Humanidades y Ciencias de la Educación.

GARCÍA ETCHEGOYEN, E. (1967). Problemas de la enseñanza del lenguaje en las escuelas primarias de la zona fronteriza con el Brasil. Montevideo: Consejo Nacional de Enseñanza Primaria y Normal. [Repartido 738]

HELLER, M. (2003). Globalization, the new economy, and the commodification of language and identity. Journal of sociolinguistics, 7,3 , p. 473-492.

HELLER, M. (2010). The commodification of languages. Annual review of anthropology, 39, p. 101-114.

HELLER, M. (2011). Patbs to Post-nationalism. A Critical Ethnograpby of Language and Identity. Oxford: Oxford University Press.

HELLER, M. (2014). The commodification of authenticity. In: Lacoste, V.; Leimgruber, J.; Breyer, T. (eds.), Indexing authenticity. Sociolinguistic perspectives. Berlín/Boston: De Gruyter, p. 136-155.

HELLER, M.; DUCHÊNE, A. (2012). Pride and profit: changing discourses of language, capital and nation-state. In: Duchêne, A.; Heller, M. (eds.), Language in late capitalism. Pride and profit. Nueva York: Routledge, p. 1-21.

HELLER, M.; DUCHÊNE, A. (2016). Treating language as an economic resource: Discourse, data and debate. In: Coupland, N. (org.), Sociolinguistics: Theoretical debates. Cambridge: Cambridge University Press, p. 139-156.

HELLER, M.; MCELHINNY, B. (2017). Language, Capitalism, Colonialism. Toward a critical bistory. Toronto: University of Toronto Press.

JAFFE, A. (2015). Defining the new speaker: theoretical perspectives and learner trajectories. International Journal of the Sociology of Language, 231, p. 21-44.

KROSKRITY, P. (2004). Language ideologies. In: Duranti, A. (ed.), A companion to linguistic antbropology. Cornwall: Blackwell Publishing, p. 496-517. 
LOPES, A. C.; SILVA, D. N. (2018). Todos nós semos de frontera: ideologias linguísticas e a construção de uma pedagogia translíngue. Linguagem em (Dis)Curso, 18, 3, p. 695-713.

MENA SEGARRA, E. (1969). Frontera y límites. Montevideo: Nuestra tierra.

MINISTERIO DE EDUCACIÓN Y CULTURA (2009). Ley General de Educación No 18437. Diario Oficial, Tomo 414, nº 27654, p. 247A-258A.

MORELLO, R. (2012). Uma política pública e participativa para as línguas brasileiras: sobre a regulamentação e a implementação do Inventário Nacional da Diversidade Lingüística (INDL). Gragoatá, 32, p. 31-41.

OROÑO, M. (2016a). El lenguaje en la construcción de la identidad nacional: los libros escolares de lectura de Vásquez Acevedo, Figueira y AbadieZarrilli. Montevideo: Tradinco.

OROÑO, M. (2016b). La escuela en la construcción de las fronteras culturales y lingüísticas en el Uruguay de fines del siglo XIX. Páginas de Educación, 9, 1, p. 137-167.

OROÑO, M. (2017). La cuestión del portugués en el Cuarto Congreso de Inspectores Departamentales de Instrucción Primaria (Uruguay, 1907). In: Acevedo, F; Nossar, K.; Viera, P. (eds.), Educación y democracia: desafíos para la transformación. Actas de las $V$ Jornadas Binacionales de Educación. Montevideo: Tradinco, p. 205-217.

O'ROURKE, B.; NANDI, A. (2019). New speakers parents as grassroot policy makers in contemporary Galicia: ideologies, management and practices. Language Policy, 18, p. 493-511.

PIETIKÄINEN, S.; KELLY-HOLMES, H. (2013). Multilingualism and the periphery. In: Pietikäinen, S.; Kelly-Holmes, H. (eds.), Multilingualism and the periphery. Nueva York: Oxford University Press, p. 1-16.

PIETIKÄINEN, S.; KELLY-HOLMES, H.; JAFFE, A.; COUPLAND, N. (2016). Sociolinguistics from the Periphery. Smal Languages in New Circumstances. Cambridge: Cambridge University Press.

"Proceso de postulación del portuñol como patrimonio cultural inmaterial" (2017). En Da Rosa, E. (comp.), Jodido bushinshe. Del bablar al ser. Portuñol como patrimonio cultural inmaterial. Montevideo: Centros MEC, p. 17-19.

REYES ABADIE, W.; BRUSCHERA, O.; MELOGNO, T. (1974). La Banda Oriental. Pradera. Frontera. Puerto. Montevideo: Ediciones de la Banda Oriental.

RONA, J. P. (1959). El dialecto "fronterizo" del Norte de Uruguay. Montevideo: Facultad de Humanidades y Ciencias.

"Seminario Jodido Bushinshe. 'Los poruñoles, os portuhnois"" (2017), In: Da Rosa, E. (comp.). Jodido bushinshe. Del bablar al ser. Portuñol como patrimonio cultural inmaterial. Montevideo: Centros MEC, p. 171-174.

SEVERO, F. (2019). Night in the north. [Traducción de Laura Cesarco Eglin y Jesse Lee Kercheval]. Latrobe: Eulalia Books.

SMEETS, R. (2004). Language as a vehicle of the intangible cultural heritage. Museum international, 56, 1-2, p. 156-165.

UNESCO (2011a) Preguntas y respuestas. Patrimonio cultural inmaterial. Disponible en: https://ich.unesco.org/doc/src/01855-ES.pdf. Acceso: 27 feb. 2021.

UNESCO (2011b). Los ámbitos del patrimonio cultural inmaterial. Disponible en: https://ich.unesco.org/doc/src/01857-ES.pdf. Acceso: 27 feb. 2021.

UNESCO (2016) Textos fundamentales de la Convención para la salvaguardia del patrimonio cultural inmaterial de 2003. París: UNESCO. Disponible en: https://ich.unesco.org/doc/src/2003_Convention_Basic_Texts-_2016_version-SP.pdf. Acceso: 27 feb. 2021.

WANG, X.; SPOTTI, M.; JUFFERMANS, K.; KROON, S.; CORNIPS, L.; BLOMMAERT, J. (2014). Globalizations in the margins. Toward a re-evalution of language and mobility. Applied Linguistics Review, 5,1, p. 23-44. 
WOOLARD, K. (2007). La autoridad lingüística del español y las ideologías de la autenticidad y el anonimato. In: Del Valle, J. (ed.), La lengua, ipatria común? Ideas e ideologías del español. Madrid/Frankfurt: Iberoamericana/Vervuert, p. 129-142.

WOOLARD, K. (2012). Introducción. Las ideologías lingüísticas como campo de investigación. In: Schieffelin, B.; Woolard, K.; Kroskrity, P. (eds.). Ideologías linguíisticas. Teoría y práctica. Madrid: Los Libros de la Catarata, p. 19-69.

WOOLARD, K. (2016). Singular and plural. Ideologies of linguistic authority in 21st century Catalonia. Nueva York: Oxford University Press.

Recebido: 28/2/2021

Aceito: 23/6/2021

Publicado: 28/6/2021 